\title{
TORNOZELEIRA ELETRÔNICA VS LIBERDADE RELIGIOSA: CONFLITOS ENTRE DIREITOS HUMANOS
}

Cleyton Heleno Pereira da Silva, Nilza Flávia de Oliveira da Costa.

Universidade do Oeste Paulista - UNOESTE. Curso de Direito, Presidente Prudente, SP. E-mail: nf oliveira2003@yahoo.com.br

\begin{abstract}
RESUMO
O objetivo deste estudo é analisar o monitoramento eletrônico, comumente conhecido como tornozeleira eletrônica, sob o prisma da Liberdade Religiosa, consagrada como um dos Direitos Fundamentais. Considerando que a religião sempre ocupou espaço na vida do indivíduo e sendo o Brasil um Estado Democrático de Direito, justificou-se a necessidade dessa pesquisa à luz dos princípios que os norteiam. Dessa forma, a pesquisa teórica possui foco na execução penal no ordenamento jurídico brasileiro em consonância com a Constituição Federal. Esta pesquisa ainda contemplou uma análise à jurisprudência pátria em caso de conflito de direitos fundamentais, bem como a longinquidade das interpretações dadas ao preceito constitucional. Os resultados constatados ao longo desse artigo explicitam que liberdade religiosa e de culto, consignados na Constituição, não é um capricho tampouco um luxo. Deste modo, aplicou-se o método hipotéticodedutivo com a utilização de doutrina, jurisprudência, artigos eletrônicos e outros.
\end{abstract}

Palavras-chaves: Liberdade religiosa, Monitoramento eletrônico, Conflito de normas, Direitos fundamentais.

\section{THE ANKLE MONITOR VS RELIGIOUS FREEDOM: CONFLICTS BETWEEN HUMAN RIGHTS}

\begin{abstract}
The objective of this study is to analyze electronic monitoring, commonly known as an electronic slide under the prism of Religious Freedom, consecrated as one of the Fundamental Rights. Considering that religion always occupied space in the life of the individual and being Brazil a Democratic State of Law, the need for such research was justified in the light of the principles that guide it. In this way, the theoretical investigation focuses on criminal enforcement in the Brazilian legal system in accordance with the Federal Constitution. This investigation still contemplated an analysis to the native jurisprudence in case of conflict of fundamental rights as well as the longitude of the interpretations given to the constitutional precept. The results found throughout this article express freedom of religion and worship, constant of the Constitution, not a whim or a luxury. The methodology to be adopted will consist of bibliographical research, with the use of doctrine, jurisprudence and electronic articles among others.
\end{abstract}

Keywords: Religious freedom, Electronic monitoring, Conflict of norms, Fundamental rights 


\section{INTRODUÇÃO}

O monitoramento eletrônico, na contemporaneidade, é um dos meios de vigilância mais sofisticados no que tange à execução penal, pois possibilita aos indivíduos apenados a progressão do regime prisional e viabiliza a prisão domiciliar caso inexistam vagas para o cumprimento da pena no regime estipulado.

Verifica-se que a implantação da tornozeleira eletrônica trouxe considerável efetividade à fase de execução penal. Com isso, desencadearam benefícios, como a diminuição do encarceramento alarmante dos últimos anos.

Nesse sentido, o chefe da Divisão de Monitoramento Eletrônico do Rio Grande do Sul, Lucas Rohde Maurer, assevera que a medida adotada é plenamente eficaz, "e permite acompanhar em tempo real a trajetória realizada pelo apenado" (MOTTA, 2017). No entanto, o monitoramento eletrônico ocasionou discussões acerca das condições impostas ao apenado para a concessão do benefício.

Ressalta-se como uma das principais discussões o conflito entre o "ius puniend" do Estado e o direito de liberdade religiosa. Este, como se sabe, foi previsto supra constitucionalmente e se encontra normatizado em diversos tratados internacionais de direito humanos.

O objetivo da presente pesquisa foi refletir sobre as condições impostas ao indivíduo condenado, a concessão do benefício da tornozeleira eletrônica assim como suas limitações. Foi utilizado na elaboração da presente pesquisa o método hipotético-dedutivo, embasando-se no entendimento doutrinário, jurisprudencial e normativo.

A finalidade da realização desta pesquisa é de produzir um conhecimento que sirva de estímulo para a realização de novas pesquisas sobre o tema abordado, aos acadêmicos das ciências jurídicas e áreas afins, proporcionando um melhor entendimento acerca de uma das mais incessantes discussões, ou seja, o conflito de direitos fundamentais.

\section{DOS DIREITOS FUNDAMENTAIS}

Comumente, a alusão aos direitos fundamentais atrela-se aos direitos humanos, que, por sua vez, são profusamente discutidos pela doutrina nacional e internacional. Entretanto, proteger a pessoa humana é um dos maiores desafios deste século XXI, uma vez que frequentemente esses direitos encontram-se em um constante processo construtivo. Diante do exposto, nota-se que os preceitos constitucionais resguardam os direitos de liberdade e suas garantias.

Nesse sentido, assevera José Joaquim Gomes Canotilho que:

[...] aos preceitos constitucionais consagradores de direitos, liberdades e garantias se atribui uma força vinculante e uma densidade aplicativa (<<aplicabilidade directa >>) que apontam para um reforço da <<mais-valia >> normativa destes preceitos relativamente a outras normas da Constituição, inclusive as referentes a outros direitos fundamentais. (CANOTILHO, 1995, p.523).

Sendo assim, verifica-se que os direitos fundamentais são: todos aqueles direitos inerentes aos seres humanos, essenciais à manutenção de uma vida digna. Estes são adquiridos a partir do nascimento com vida. Ressalta-se que os direitos fundamentais encontram-se preconizados à luz do princípio da dignidade da pessoa humana, visto esse ser o valor supremo de uma democracia. (SILVA, 2000, p.147)

Neste sentido, Silva ressalta que:

A dignidade da pessoa humana não e uma criação constitucional, pois ela é um desses conceitos a priore, um dado preexistente a toda experiência especulativa, tal como a própria pessoa humana. A constituição, reconhecendo a sua existência e a sua eminencia, transforma-a num valor supremo a ordem jurídica, quando a declara como um dos fundamentos da república federativa do Brasil constituída em estado democrático de direito. (SILVA, 2000, p. 146). 


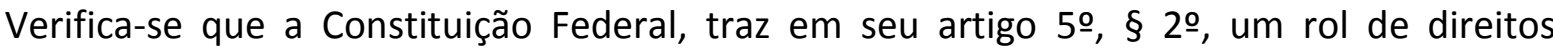
fundamentais meramente exemplificativos, já que não se excluem outros direitos fundamentais decorrentes do regime, dos princípios e dos tratados internacionais. Dessa forma, afirma-se que esse rol não pode ser considerado taxativo, conforme se nota na transcrição abaixo:

\section{Art. $50[\ldots]$}

$\S$ 2o Os direitos e garantias expressos nesta Constituição não excluem outros decorrentes do regime e dos princípios por ela adotados, ou dos tratados internacionais em que a República Federativa do Brasil seja parte. (BRASIL, 1988).

Deste modo, leciona Ferreira Filho (2015, p. 326) que:

Nossa magna carta admite haver outros direitos fundamentais além dos enumerados, direitos estes implícitos. Tais direitos, como deflui § 20 do art. 50, seriam "decorrentes do regime de princípios" (dentre estes essencialmente o da dignidade humana) que a Constituição adota.

Assim, ao refletir sobre os Direitos e Garantias Fundamentais, percebe-se que suas normas não se encontram respaldadas apenas na própria Constituição, pois esta não exclui a possibilidade de existência de outras garantias fundamentais, conforme previsto no §2o do artigo 5o, citado anteriormente.

\section{CHOQUE ENTRE NORMAS DE DIREITOS HUMANOS}

Constata-se que o choque e a concorrência entre as normas de direitos humanos não são incomuns, e "resolver esses conflitos entre colisões de direitos fundamentais do indivíduo desafia os operadores de direito e a sociedade como um todo" (MAZZUOLI; SORIANO, 2009, p. 82).

Leciona Flávia Piovesan (apud MAZZUOLI, 2001, p. 83): "todos os direitos humanos constituem um complexo integral, único e indivisível, em que diferentes direitos estão necessariamente inter-relacionados e interdependentes entre si".

Desse modo, é possível afirmar que os direitos humanos constituem uma unidade indivisível.

Ressalta-se que a Carta Magna, ao instituir em suas disposições o princípio da dignidade da pessoa humana, consagra e reconhece um indivíduo apenado como pessoa humana. Logo, o Estado deve assegurar-Ihe condições humanamente adequadas para que cumpra sua pena com o respeito que lhe corresponde por sua dignidade humana. (LUISI, 2003, p. 47).

O "ius puniend" concedido ao Estado cerceia o direito de liberdade de um indivíduo, a fim de garantir segurança social e buscar a ressocialização do infrator. Muitas vezes isso ocorre restringindo e impossibilitando o acesso a outros direitos fundamentais consagrados pela Constituição de 1988, como o direito à liberdade religiosa.

O Estado, como titular do direito de punir, ou seja, o possuidor do "ius puniend", busca, através do cerceamento da liberdade de indivíduos infratores, resguardar um dos princípios constitucionais coletivos, isto é, o direito de segurança da população. Ao retirar do convívio social um agente delinquente, assegura à sociedade esse direito fundamental.

Bozza (2016), sobre esse tópico, entende: "que a prisão não seria entendida nem como medida cautelar, nem como antecipação de pena, mas apenas uma medida do Estado destinada a promover o direito fundamental à segurança pública".

O Estado, ao praticar tal conduta e resguardar o direito fundamental à segurança, fere, todavia, outros direitos fundamentais, como o próprio direito à liberdade religiosa, visto que este se encontra fulcro no artigo 5o incisos VI e VII. Isso ocorre porque ao apenado, impossibilitado de se locomover, inviabiliza-se sua liberdade religiosa. Nota-se, portanto, um conflito entre normas de natureza fundamental: de um lado, encontra-se o Direito de segurança praticado pelo Estado em Pro societate; de outro, está o direito de liberdade religiosa do apenado.

A Constituição Federal em seu artigo 5o, incisos VI e VII, afirma que: 
Art. 5ㅇ in omissis]

VII - é assegurada, nos termos da lei, a prestação de assistência religiosa nas entidades civis e militares de internação coletiva. (BRASIL, 1988).

Embora esse direito esteja assegurado pela Constituição, em alguns casos ele é restrito. Insta destacar que, na colisão entre direitos humanos e o ius puniend, devem-se priorizar os direitos fundamentais individuais "considerando em primeiro plano o ser humano, objeto imediato das tutelas constitucionais". (MAZZUOLI, 2009, p.71).

Assim, verifica-se que, ao possibilitar a implantação do monitoramento eletrônico, assegura a sociedade um de seus direitos previstos constitucionalmente. Desse modo, existe um conflito aparente entre o direito à liberdade religiosa assegurada ao apenado e o direito de segurança da sociedade.

\section{USO DE TORNOZELEIRA ELETRÔNICA}

A monitoramento eletrônica é algo novo em nosso ordenamento jurídico, sendo prevista, inicialmente, na Lei no. 12.258/2010 que alterou a Lei de Execução Penal (Lei n. 7.210/1984). A implantação e a utilização desse modelo de monitoramento ocorreram em virtude de frear o encarceramento em massa, possibilitando à administração penitenciária acompanhar passo a passo o vigiado. Ademais, esse meio acarretou não só benefícios ao apenado, como também ao Estado.

Neste diapasão, nota-se que os benefícios avocados não se referem tão somente ao apenado, como também aos cofres públicos. Nesse sentido, pontifica o departamento penitenciário (DEPEN) que as vantagens do monitoramento consistem em:

[...] evitar que investigados e condenados entrem em contato com o ambiente estigmatizante das prisões, a monitoração eletrônica também traz economia aos cofres públicos. Enquanto um preso custa, em média, R\$ 1,8 mil por mês, a monitoração eletrônica de uma pessoa pode custar de $\mathrm{R} \$ 200$ a $\mathrm{R} \$ 600$ mensais, dependendo dos termos contratuais da empresa fornecedora dos equipamentos, informou o órgão federal. Podendo ser aplicado em pessoas consideradas em situação de vulnerabilidade dentro do sistema prisional, como, por exemplo, gestantes, portadores de doenças infectocontagiosas, condenados maiores de 70 anos de idade, mulheres com filho menor e portadores de deficiência física ou mental. (BRASIL, 2015).

Reconhece-se que o monitoramento eletrônico faz-se extremamente relevante devido aos inúmeros benefícios ofertados à fase de execução, pois se reduz o número de indivíduos encarcerados, além de possibilitar monitoramento em tempo real, o que assegura ao condenado o cumprimento de sua pena no seio familiar.

\section{RESTRIÇÃO AO DIREITO DE CRENÇA RELIGIOSA E O CONDICIONAMENTO DA TORNOZELEIRA ELETRÔNICA}

Ao longo da história, o tema "Religião e Estado" sempre esteve em discussão. Buscou-se refletir sobre o conflito existente entre o direito de punir do Estado, a liberdade do indivíduo e a sua liberdade religiosa.

Ressalta-se que uma das funções da pena é a ressocialização do condenado. Assim, mesmo exercendo o direito de punir, o Estado busca reinserir o indivíduo na sociedade.

A liberdade religiosa, por sua vez, é um dos direitos fundamentais do homem e constitucionalmente assegurada, mesmo no contexto prisional. Acredita-se, portanto, que "a religião se apresenta de forma positiva, como fonte de princípios morais úteis à sociedade". (SORIANO, 2012, p.23).

No âmbito da execução penal, a garantia é regulamentada no artigo 24 da Lei no $7.210 / 84$, o qual prevê a realização de "serviços organizados no estabelecimento penal". 
Salienta-se que o artigo 5으, VII impõe ao Estado o dever de proporcionar ações que busquem dar cumprimento ao preceito constitucional. Desse modo, inúmeros religiosos frequentam estabelecimentos prisionais, pois "visa-se, por meio da assistência religiosa, a busca da mais completa ressocialização daquele que se encontra em um estabelecimento de internação coletiva em virtude de sua natureza pedagógica". (BRASIL, 1981).

Não se buscou refletir sobre o direito à liberdade de ir e vir, mas aquele assegurado constitucionalmente, resguardando ao preso ou internado em um estabelecimento prisional a liberdade religiosa no que concerne participar de cultos ou atividades religiosas.

Não é lícito ao Estado cercear o direito do preso de participação a celebrações religiosas ao Ihe conceder a tornozeleira eletrônica. Vale ressaltar que o apenado, durante a clausura, inseriuse em uma comunidade religiosa, e requerer do réu a concordância com uma série de limitações dentre os quais recolher-se em casa ou dela não afastar-se tolhendo o de participar de cultos ou liturgias, acaba restringindo ou eliminando seu direito de liberdade religiosa

Como salienta Silva (2014, p.250), a liberdade religiosa:

Se inclui entre as liberdade espirituais. Sua exteriorização é forma de manifestação do pensamento. Mas, sem duvida, é de conteúdo, mas complexo pelas implicações que sucinta. Ela compreende três formas de expressão (três liberdades): (a)liberdade de crença; (b) a liberdade de culto; (c) e a liberdade de organização religiosa. Todas elas estão garantidas na Constituição. (SILVA, 2014, p. 250).

Diante dessa realidade, infere-se que, com a utilização do monitoramento eletrônico, o indivíduo apenado encontra-se cerceado de praticar seu direito de liberdade religiosa. Os tribunais concebem analogamente essa ideia, pois vêm entendendo que o condicionamento para a concessão de monitoramento eletrônico fere drasticamente o direito a prática de liberdade religiosa. Assim, ao aplicar tal medida, deve-se observar para que tal garantia fundamental seja respeitada.

O Tribunal de Porto Alegre, em consonância aos apontamentos levantados, entende que a prática do direito de liberdade possui caráter ressocializador e deve ser assegurado:

AGRAVO DA EXECUÇÃO (ART. 197 DA LEP). PERMISSÃO PARA FREQUENTAR CULTOS RELIGIOSOS AO APENADO EM PRISÃO DOMICILIAR. No cotejo entre o interesse da administração prisional e o direito do apenado ao exercício da sua crença religiosa, representada pela sua frequência aos cultos religiosos, deve prevalecer o que trata da liberdade do cidadão. Retirar do apenado o direito de frequentar os cultos religiosos, em detrimento do interesse estatal e porque restaria dificultosa a fiscalização do cumprimento da prisão domiciliar, significa restringir o âmbito de aplicação de institutos de valor real à sua máxima ressocialização, maximamente expressada pelo princípio da individualização da pena. Agravo provido.(BRASIL, 2018, p.1)

Assim, entende-se que o constrangimento da pessoa humana, para que renuncie sua fé como forma de lograr a concessão de um benefício, representa mais que um desrespeito. É também uma violação constitucional, visto que a Constituição Federal, ao consagrar a inviolabilidade da crença religiosa, está também assegurando plena proteção à liberdade de culto e liturgias. (BRASIL, 1988).

Destarte, deve o Estado atuar de forma a assegurar os direitos fundamentais do indivíduo, cabendo aqui ressaltar que "el ejercicio del ius puniend en un Estado democrático no puede arrumbar las garantias del Estado de Derecho".(PIUG, 1982, p.29).

Nota-se que condicionar determinadas circunstâncias ao apenado, como limitação territorial para a obtenção do monitoramento eletrônico, fere direitos fundamentais como a liberdade religiosa, além das demais garantias constitucionais, cláusulas pétreas. 


\section{CONCLUSÃO}

Ao findar breves considerações, faz-se necessário reafirmar que o papel fundamental do Estado Democrático de Direito consiste em resguardar os direitos fundamentais individuais.

Verifica-se que o monitoramento, realizado por intermédio da tornozeleira eletrônica, interfere nitidamente no exercício das atividades religiosas.

Salienta-se, no entanto, ser alentador o posicionamento jurisprudencial, deferindo ao apenado o direito de frequentar os cultos religiosos, em local, dias e horários determinados. Desse modo, possibilitaria a aplicação de um dos institutos muito valiosos para a ressocialização.

Portanto, nesse contexto fático-jurídico, o pedido para autorização a cultos religiosos, ainda que leve em conta o caso concreto, não alcança outra solução senão a permissão de alteração do zoneamento eletrônico, com vistas a que seja possível ao apenado frequentar o culto religioso que lhe convém.

Conclui-se que a liberdade religiosa, na qual se inclui a liberdade de crença e a liberdade de culto, constante da Constituição, não pode ser tratada como um capricho, tampouco um luxo, mas uma necessidade, um direito fundamental, devendo ser respeitado. Tal respeito a esse direito é, porém, ínfimo, uma vez que se prioriza o interesse público e social, o que acarreta no abandono de um dos pilares básicos para a ressocialização - tão necessária em tempos em que se reinam atitudes egocêntricas e imediatistas.

\section{REFERÊNCIAS}

BOZZA, Fabio da Silva. Segurança não é direito fundamental. 2016. Disponível em: $<$ https://canalcienciascriminais.com.br/seguranca-nao-e-direito-fundamental/>. Acesso em 04 Maio 2018.

BRASIL, República Federativa do. Constituição federal de 1988. Promulgada em 5 de outubro de 1988.

BRASIL. Tribunal de Justiça do Rio Grande do Sul. AGRAVO DA EXECUÇÃO (ART. 197 DA LEP). PERMISSÃO PARA FREQUENTAR CULTOS RELIGIOSOS AO APENADO EM PRISÃO DOMICILIAR. AG №. 70.058.084.393AG/M 2.161 - S 30.01.2014 - P 102. Relator: Aymoré Roque Pottes de Mello. Porto Alegre, 30 de Janeiro de $2014 . \quad$ Disponível em:<https://tjrs.jusbrasil.com.br/jurisprudencia/113759903/agravo-agv-70058084393-rs>. Acesso em 08 Maio de 2018.

BRASIL. Supremo Tribunal Federal. RECURSO EXTRAORDINARIO. 92916/PR, 1a Turma, Rel. Min. Antonio Neder, j. 19.5.1981, RTJ 100/329 Relator: Antonio Neder. Disponível em: <https://stf.jusbrasil.com.br/jurisprudencia/14692363/recurso-extraordinario-re-92916-pr>. Acessado em 14 Maio 2018.

BRASIL, Conselho Nacional de Justiça. Qual a utilidade e como funcionam?. 2015. Disponível em: <http://www.cnj.jus.br/noticias/cnj/77247-qual-a-utilidade-e-como-funcionam>. Acesso em: 03 Maio 2018

CANOTILHO, José Joaquim Gomes. Direito constitucional. 6 ed. Coimbra. Almedina: 1995, p. 523. LUISI, Luiz. Os princípios constitucionais penais. Ed. 2. Porto Alegre: 2003 p. 47.

MAZZUOLI, Valério de Oliveira, SORIANO, Aldeir Guedes. Direito a liberdade religiosa: Desafios e perspectiva para o século XXI. Belo Horizonte: Fórum, 2009 p. 71-82. 
MAZZUOLI, Valério de Oliveira. Direito internacional: Tratados e direitos humanos fundamentais na ordem jurídica brasileira. Rio de Janeiro: América jurídica, 2001 p.83.

MOTTA, Neiva. Pesquisa aponta que tornozeleira eletrônica oferece menor percentual de reincidência no sistema prisional. 2017. Disponível em:

< http://www.susepe.rs.gov.br/conteudo.php?cod_menu=4\&cod_conteudo=2889>. Acesso em 14 Maio 2018

PUIG. Santiago Mir. Función de la pena y teoria del delito en el estado social y democrático de derecho. Ed.2. Barcelona: Bosch, 1982 p.29

SILVA, José Afonso da. Poder constituinte e poder popular: estudos sobre a constituição. São Paulo. Malheiros: 2000 p, 147.

SILVA, José Afonso da. Curso de direito constitucional positivo. 37 ed. São Paulo: Malheiros, 2014 p, 250.

SORIANO, Aldeir Guedes. Direitos humanos e liberdade religiosa: Da teoria à prática. Ed.1. São Paulo: Kit's, 2012 p. 23. 